Copyright (C1996, American Institute of Aeronautics and Astronautics, Inc.

AIAA Meeting Papers on Disc, January 1996

A9618806, AIAA Paper 96-0853

\title{
Development of a high-pressure detonation-driven shock tube facility
}

\section{Donald R. Wilson}

Texas Univ., Arlington

Frank K. Lu

Texas Univ., Arlington

W. S. Stuessy

Texas Univ., Arlington

Karl R. Burge

Texas Univ., Arlington

\section{AIAA 34th Aerospace Sciences Meeting and Exhibit, Reno, NV Jan 15-18, 1996}

The Hypersonic Shock Tunnel at The University of Texas at Arlington is being converted from a pressure-driven to a detonation-driven shock tunnel. This modification was necessitated by a requirement to provide a high pressure/temperature test environment for research to support the development of MHD-augmented hypersonic test facility concepts. A description of the existing shock tunnel, review of the detonation-driven shock tunnel concept, predicted performance of the detonation-driven shock tunnel, and results from an experimental simulation of the tunnel operation, are provided. (Author) 


\title{
DEVELOPMENT OF A HIGH-PRESSURE DETONATION-DRIVEN SHOCK TUBE FACILITY
}

\author{
Donald R. Wilson*, Frank K. Lư ${ }^{\dagger}$, W. Scott Stuessy ${ }^{\ddagger}$ and Karl R. Burge \\ NASAUUTA Center for Hypersonic Research \\ The University of Texas at Arlington \\ Arlington, TX 76019
}

\begin{abstract}
The Hypersonic Shock Tunnel at The University of Texas at Arlington (UTA) is being converted from a pressure-driven to a detonation-driven shock tunnel. This modification was necessitated by a requirement to provide a highpressure, high-temperature test environment for research to support the development of MHDaugmented, hypersonic test facility concepts. A description of the existing shock tunnel, review of the detonation-driven shock tunnel concept, predicted performance of the detonation-driven shock tunnel, and results from an experimental simulation of the tunnel operation are provided in this paper.
\end{abstract}

\section{Introduction}

The NASAIUTA Center for Hypersonic Research is supporting MSE, Inc. in a NASAsponsored program to develop MHD-augmented hypersonic test facility concepts. A principal goal of this effort is to investigate concepts that could provide the basis for development of a continuous-flow hypersonic wind tunnel optimized for testing advanced air-breathing hypersonic propulsion systems. ${ }^{1}$ in particular, a need exists for a facility capable of providing post bow shock conditions for testing advanced concepts such as the Pre-Mixed, Shock-Induced Combustor (PM/SIC) Engine. ${ }^{2}$ In order to simulate this test environment in an MHDaugmented test facility, preliminary design studies indicate that accelerator channel static pressures on the order of 100 atm may be required. $^{3}$

\footnotetext{
"Professor of Aerospace Engineering, Associate Fellow

${ }^{\dagger}$ Associate Professor of Aerospace Engineering, Associate Fellow

*Faculty Research Associate; Member

'Graduate Student, Student Member
}

Copyright $\odot 1996$ by the American Institute of Aeronautics and Astronautics, Inc. All rights reserved.
Unfortunately, the previous experience base for MHD accelerator channel operation was at pressure levels on the order of 1 to $10 \mathrm{~atm} .{ }^{4,5}$ Development of MHD accelerators capable of operating at high pressure levels will require improved understanding of a variety of technical issues, such as the effect of high pressure on the electrical conductivity and Hall parameter of both equilibrium and non-equilibrium plasmas, the structure and stability of the current discharge, and the plasma electrical breakdown characteristics. Furthermore, the development of novel ionization concepts such as the use of high-energy microwave or electron beams may provide an attractive alternative to the use of alkali metal seeding for attaining the requisite electrical conductivity. ${ }^{6,7}$ Prior experience with these schemes is also at relatively low pressure, and their feasibility at high pressure will require experimental validation.

In order to provide an experimental capability to address some of the issues related to highpressure operation of MHD accelerators, UTA has proposed to convert its existing pressuredriven hypersonic shock tunnel $\left.\right|^{8,9}$ into a detonation-driven shock tunnel. Other concepts for enhancing the performance of the existing facility were briefly considered, including the use of an electrical ${ }^{10,11}$ or combustion- heated ${ }^{12}$ light gas driver, and a free piston driver. ${ }^{13}$ Although the free piston driver probably has the highest performance capability, Bakos and Erdos ${ }^{14}$ have concluded that the detonation driver may offer comparable performance with reduced capitol investment. Furthermore, an experience base has been generated at UTA to support this approach via an ongoing research program to develop Pulse Detonation Engine (PDE) concepts. ${ }^{15,16}$ Much of the technology developed as part of this program would be directly applicable to the detonation-driven shock tunnel.

The results of a design study to explore the feasibility of converting the UTA shock tunnel to 
a detonation-driven facility are presented in this paper. The basic simulation requirements needed to support the MHD accelerator development program were:

$\begin{array}{ll}\text { Pressure } & 0.01-100 \text { atm } \\ \text { Temperature } & 2200-4000 \mathrm{~K} \\ \text { Mach number } & \approx 2.0\end{array}$

These values were felt to be representative of accelerator channel entrance flow conditions for an MHD-augmented facility capable of providing the test section environment needed for testing of advanced hypersonic engine concepts. Experimental simulations of several detonationdriven shock tunnel modes of operation were also conducted by configuring the existing PDE research combustor as a shock tube. The results of these tests, together with the numerical simulations conducted as part of the design study led to the selection of the design configuration for the UTA facility. Predicted facility performance maps for simulation of accelerator entrance flow conditions are presented.

\section{Description of the Existing Shock Tunnel}

A schematic of the existing shock tunnel facility is shown in Fig. 1. The shock tube consists of a $15.24 \mathrm{~cm}$ (6 in) diameter, $3 \mathrm{~m}$ long driver tube, separated from a $15.24 \mathrm{~cm}$ diameter, $8.23 \mathrm{~m}$ (27 ft) long driven tube by a double-diaphragm section. Both driver and driven tubes are rated for a pressure of $41.3 \mathrm{MPa}(6,000 \mathrm{psi})$. Diaphragms are normally 10 gauge $(3.42 \mathrm{~mm})$ hot-rolled ASTM A36 steel plates, scored to various depths in a cross potent pattern. The nozzle, test section and diffuser were donated to UTA by LTV Aerospace and Defense Co. (now Loral Vought) of Dallas, Texas. A $7.5^{\circ}$ halfangle conical nozzle with interchangeable throat inserts enables Mach numbers of 5 through 16 to be obtained. Presently, the tunnel is configured for Mach 8. The exit diameter of the nozzle is $33.6 \mathrm{~cm}(13.25 \mathrm{in})$. A secondary diaphragm made of $0.0127 \mathrm{~mm}(0.005 \mathrm{in})$ thick aluminum sheet is located in the nozzle throat region, and is used to separate the driven-tube gas from that in the test section. The test section is of semi-free jet design, $53.6 \mathrm{~cm}(21.1$ in) long and $44.0 \mathrm{~cm}$ (17.5 in) in diameter. Two $23.0 \mathrm{~cm}$ (9 in) diameter optical windows are located on opposite sides of the test section.
Instrumentation and model mounting ports are located in the floor of the test section, and in the floor and roof of the diffuser. A $30.5 \mathrm{~cm}$ (12 in) diameter, $213 \mathrm{~cm}$ (84 in) long diffuser connects the test section to a $4.25 \mathrm{~m}^{3}\left(150 \mathrm{ft}^{3}\right)$ vacuum tank.

The pneumatic system consists of a Haskell model 55696 two-stage gas-driven booster pump capable of charging the driver tube to $41.3 \mathrm{MPa}$ (6000 psi). The Haskell pump is normally connected to the facility air compressor system, consisting of a Clark CMB6 5-stage air compressor, twin-tower desiccant drier, and $16.6 \mathrm{MPa}(2400 \mathrm{psi})$ storage bottles. Alternatively, the Haskell pump can be fed from a manifold of $15.2 \mathrm{MPa}(2200 \mathrm{psi})$ helium storage bottles. The vacuum system consists of a Sargent-Welch model $1376(300 \mathrm{l} / \mathrm{min})$ pump used to evacuate the driven tube, a SargentWelch model $1396(2800 \mathrm{l} / \mathrm{min})$ pump used to evacuate the test section/diffuser/vacuum tank, and a vacuum pressure measurement system consisting of two Baratron type 127A pressure transducers and the associated valve system to enable full range coverage from 1000 to 0.001 Torr.

Standard shock tube instrumentation, consisting of a variety of Kulite and PCB pressure transducers, Medtherm thin film heat flux sensors, and Medtherm fast-response thermocouples is available. The data is collected by a LeCroy 40 channel data acquisition system. Eight high-speed channels are provided by LeCroy model 6810 waveform recorders $(5 \mathrm{MHz})$, and the remaining low-speed 32 channels by a LeCroy model $8212 \mathrm{~A}$ data logger $(40 \mathrm{kHz})$ The data is recorded into onboard memory within the CAMAC (IEEE-583) crate, and transferred via a GPIB-488 bus to a $486 \mathrm{PC}$ computer for post-run processing.

\section{Detonation-Driven Shock Tunnel Concept}

The detonation-driven shock tube was first proposed by Bird ${ }^{17}$ in 1957, and has since been studied by several investigators. ${ }^{14,18-23} \mathrm{~A}$ detonation process is typically established in a driver tube filled with a near-stoichiometric mixture of hydrogen and oxygen, although other gas combinations are possible. The initial pressure level prior to detonation can be quite low, thus eliminating the need for thick metal 
diaphragms. The detonation process produces a relatively low molecular weight driver gas at high temperature and pressure levels. The sudden pressure rise produced by the detonation wave causes the primary diaphragm to rupture, thus establishing a shock wave in the driven tube filled with air. Two modes of operation are possible. In the "upstream propagation" mode (Fig. 2), the ignition source is placed just upstream of the primary diaphragm, producing a detonation wave that propagates from right to left through the driver tube. The pressure rise following the detonation wave ruptures the primary diaphragm to establish the flow in the driven tube. The effective driver tube conditions for this mode are the pressure and temperature at state 4 ' on the wave diagram in Fig. 2. In the "downstream propagation" mode (Fig. 3), the ignition source is located at the upstream end of the driver tube, producing a detonation wave that travels from left to right through the driver tube, rupturing the primary diaphragm on impact. The effective driver tube conditions for this mode are those for state 4 " on the wave diagram shown in Fig. 3. For either mode, further performance enhancement is possible by helium dilution of the hydrogen/oxygen driver tube mixture. The helium dilution raises the sonic speed in the driver gas, and also somewhat reduces the danger associated with premature detonation of the hydrogen/oxygen mixture. Performance calculations by $\mathrm{Yu}$, et al. ${ }^{21}$ indicate that the performance degradation caused by the slight lowering of the detonation temperature is more than adequately offset by the increased sonic speed of the driver-tube gas.

\section{Facility Design/Performance Analysis}

Design and performance analysis calculations for the detonation-driven shock tunnel were made with the aid of the TEP ${ }^{24}$ computer code, a Windows ${ }^{\text {TM }}$ version of the NASA CEC76 ${ }^{25}$ code This code provides real-gas calculations of a variety of basic gasdynamic processes, such as Chapman-Jouguet detonation waves, shock tube and isentropic nozzle performance. A quasi-one-dimensional flow model is assumed, and real gas calculations based on both equilibrium and frozen flow models are available. All of the calculations presented in this paper are based on the equilibrium flow assumption. The basic geometric configuration shown in Fig. 1 was retained, along with the 6000 psi pressure limitation for both the driver and driven tube.

The TEP ${ }^{T M}$ code was first used to calculate detonation tube performance for stoichiometric mixtures of hydrogen and oxygen, for a range of initial pressures and varying levels of helium dilution. The TEP ${ }^{T M}$ code was also used for shock tube performance calculations, however the code does not include the unsteady expansion between driver and driven tube. A code developed at UTA ${ }^{26}$ that calculated the driven-tube pressure ratio, $p_{2} / p_{1}$, and shock speed as a function of the effective shock tube pressure ratio, $p_{4} / p_{1}$, was used for this purpose. This is a perfect gas code, but prior comparisons with real gas codes indicate that the driven tube incident wave pressure ratio and wave speed is generally within 5 percent. The TEP ${ }^{T M}$ code was then used to calculate the temperature ratio across the expansion wave, the properties following the incident and reflected waves in the driven tube, and the subsequent isentropic nozzle expansion.

A series of preliminary calculations quickly indicated that operation of the detonation driver in the "upstream" mode (Fig. 2) precluded the attainment of the desired 100 atm static pressure level in the subsequent nozzle expansion, without exceeding the 6000 psi pressure limit of the driver tube. For this mode, the maximum pressure occurs when the detonation wave reflects from the end wall of the driver, and pressure levels of the order of 9000 psi were predicted for operating conditions that would produce driven tube $p_{5}$ pressure levels high enough to obtain a static pressure level of $100 \mathrm{~atm}$ when expanded to Mach 2. Thus, the operating mode employing downstream propagation of the detonation wave (Fig. 3) was selected as the basis for the facility performance calculations.

The predicted performance map for the "downstream propagation" mode corresponding to Mach 2 nozzle flow is shown in Fig. 4. A stoichiometric mixture of hydrogen and oxygen in the driver (no helium dilution) was assumed. The corresponding performance envelopes using air and helium as driver tube gases are also shown for comparison. The performance enhancement provided by the detonation driver 
is considerable, and although the specified static temperature levels were easily achieved, a maximum pressure of only 50 atm was predicted. However, by either reducing the nozzle expansion to a Mach number of 1.6, or by adding helium dilution on the order of 50 percent, the target pressure level of 100 atm could be reached.

\section{Simulation Experiments}

UTA has been actively involved in an on-going Pulse Detonation Engine (PDE) research program. ${ }^{15,16}$ The PDE research combustor developed as part of this program was reconfigured as a detonation-driven shock tube in order to provide experimental validation of the proposed concept.

\section{PDE Test Facility}

A schematic diagram of the PDE research facility is shown in Fig. 5. Principal components include the research combustion chamber (Fig. 6), fuel/oxidizer system, fuel/air system, ignition system, purge air system, vacuum system and data acquisition/control system. A complete description of the facility as provided in Refs. 15,16 .

The combustion chamber is constructed from $7.62 \mathrm{~cm}$ ( $3 \mathrm{in})$ diameter steel tube sections of varying lengths. Each section has provisions for mounting pressure transducers, heat flux sensors, and thermocouples at $7.62 \mathrm{~cm}$ intervals along the principal axis of the tube. One section of $7.62 \mathrm{~cm}$ length contains the arc igniter plug. This section may be placed at either end of the tube, or at intermediate locations. The fuel and oxidizer, as well as the purge air, are injected into the chamber through an end flange that also contains a pressure transducer. Mylar diaphragms of $0.254-0.381$ $\mathrm{mm}(0.01-0.015 \mathrm{in})$ thickness are used to seal the open end of the tube. These diaphragms rupture upon impact of the detonation wave, and the combustion products are exhausted into the facility exhaust system. The vacuum system is used to pump the sealed chamber to a pressure on the order of $690 \mathrm{~Pa}(0.1 \mathrm{psia})$ and then the fuel and oxidizer are injected into the chamber from standard high pressure storage bottles through a pressure regulation system. Matheson series 6103 flash arrestors are installed in the lines to prevent flashback into the fuel and oxidizer tanks in the event of a premature ignition during the filling operation. The pressure in the chamber is monitored during the filling operation by a precise Baratron model 127A vacuum pressure transducer, and the method of partial pressures is used to set the mixture ratio.

The fuel/oxidizer mixture is ignited by a high energy electric arc. A Miller snap-start high frequency arc welder power supply capable of providing open circuit voltages up to $30 \mathrm{kV}$ is used to preionize the gap between two flushmounted electrodes. Once breakdown occurs in the gap between the two electrodes, a capacitor bank containing two $11,000 \mu \mathrm{F}$ capacitors connected in series to provide a maximum load voltage of 150 volt discharges a high current arc across the gap. The estimated energy delivered in the arc is approximately 3-5 Joule.

A DSP Technology data acquisition/control system is used to collect data during a test firing. This system provides 48 data channels, each containing an independent amplifier, 12 bit, $100 \mathrm{kHz}$ analog-to-digital converter, and 20 $\mathrm{kB}$ memory unit. All channels are sampled simultaneously. Transient chamber pressures were measured with PCB model 111a24 dynamic pressure transducers, rated at 6.89 $\mathrm{MPa}(1000 \mathrm{psi})$, and having a response time of $1 \mu \mathrm{sec}$. The data acquisition system was connected to a 486-DX $33 \mathrm{MHz}$ IBM-compatible PC via a GPIB 488 bus.

\section{Experimental Results - PDE Combustor}

Prior to presenting the results of the shock tube simulation experiments, a brief review of selected results from the basic PDE experimental program ${ }^{15,16}$ will be given. In particular, phenomena relevant to the establishment of detonation waves in the driver will be reviewed. In the PDE program, detonations with near stoichiometric mixtures of hydrogen, propane, or methane and oxygen have been achieved. A typical pressure trace from a hydrogen-oxygen run at an initial pressure of $2 \mathrm{~atm}$ is shown in Fig, 7. The pressure traces are from pressure transducers located at $7.62 \mathrm{~cm}(3 \mathrm{in})$ intervals, with the first sensor located $7.62 \mathrm{~cm}$ from the igniter. The average wave propagation speed between adjacent pressure transducers was calculated from 


$$
u_{s}=\frac{\Delta x}{\Delta t}
$$

and average wave speeds for different initial pressures are compared in Fig. 8 for the hydrogen-oxygen runs. In addition, Fig. 8 includes calculations of wave speed based on the measured pressure ratio of the propagating wave, however this approach does not provide consistent results. Also shown in Fig. 8 are the sonic speed and the theoretical ChapmanJouguet detonation wave speed. These values were calculated from the TEP ${ }^{T M}$ code. The observed wave pattern is clearly pressure dependent. At $0.5 \mathrm{~atm}$, the wave appears to be a deflagration (subsonic) wave, whereas at 1 atm a weak (low supersonic) detonation is observed. At $2 \mathrm{~atm}$, a weak detonation wave is formed that appears to transition to a ChapmanJouguet detonation wave between the third and fourth pressure transducer. The transition location is also dependent upon fuel/oxidizer combination, mixture ratio, and turbulence enhancement. $^{15}$ Surprisingly, the ignition energy level was not found to be a significant factor in either the location or occurrence of the transition. This may be due to the fact that sufficient energy was available from the ignition system to produce the weak detonation wave for all of the levels tested. Further tests are planned to explore the effect of ignition energy level, and in particular, to determine if an energy threshold for direct initiation of a $\mathrm{CJ}$ detonation wave exists that is within the capability of the current system. The ability to directly initiate a $\mathrm{CJ}$ detonation will clearly have a significant influence on the "upstream propagation" mode of operation.

The classical Zeldovich, von Neumann and Doring (ZND) model ${ }^{28}$ for a detonation wave is illustrated in Fig 9. Their model assumes a propagating normal shock wave that compresses the gas from its initial state to a high pressure state referred to as the von Neumann spike. The pressure ratio across this wave is given (for a perfect gas) from classical shock wave theory,

$$
\frac{p_{s}}{p_{1}}=1+\frac{2 \gamma_{1}}{\gamma_{1}+1}\left(M_{1}^{2}-1\right)
$$

The corresponding temperature rise associated with the shock wave initiates chemical reactions in the combustible mixture after a short ignition delay, and the state gradually approaches an equilibrium state predicted by ChapmanJouguet theory

$$
\frac{p_{2}}{p_{1}}=\frac{1+\gamma_{1} M_{1}^{2}}{1+\gamma_{2}}
$$

The Chapman-Jouguet wave propagation speed for a stoichiometric hydrogen/oxygen mixture at 2 atm is $2879 \mathrm{~m} / \mathrm{sec}$, corresponding to a shock Mach number of 5.35. Substituting this value into Eqs. (2) and (3) gives $p_{s} / p_{1}=33.23$ and $\mathrm{p}_{2} / \mathrm{p}_{1}=19.8$. The experimentally observed pressure ratios are on the order of 12.6, which is closer to but lower than the $\mathrm{CJ}$ pressure ratio of 19.8. The duration of the von Neumann spike is only expected to be on the order of several microseconds, ${ }^{28}$ thus the $100 \mathrm{kHz}$ sampling frequency of the DSP data acquisition system may miss the peak pressure level. In fact, subsequent tests in which the pressure traces were recorded on a $300 \mathrm{MHz}$ digital oscilloscope verified that this often occurs. The reason for the discrepancy between the observed pressure ratio and the $\mathrm{CJ}$ pressure ratio is not obvious, but is consistently observed in all of our results.

\section{Shock Tube Confiquration}

The PDE research chamber was reconfigured as a detonation-driven shock tube by inserting a Mylar diaphragm at a flange interface to separate the driver tube section containing the appropriate fuel/oxidizer/diluent mixture from the driven tube containing air. The length of the driver tube was $53.3 \mathrm{~cm}$ (18 in), and the driven tube was $30.5 \mathrm{~cm}(12 \mathrm{in})$. The driver tube contained two transducers, located $15.24 \mathrm{~cm} 6$ in) apart, whereas the driven tube contained 4 transducers located at $7.62 \mathrm{~cm} \mathrm{(3} \mathrm{in)} \mathrm{intervals.}$ The first transducer in the driven tube was 3.81 $\mathrm{cm}$ (1.5 in) downstream of the diaphragm. Tests were run with the igniter located at both upstream and downstream ends of the driver tube.

\section{Experimental Results - Simulated Shock Tube}

For the simulated detonation-driven shock tube experiments, the driver tube was filled with near-stoichiometric mixtures of hydrogen and oxygen. The initial pressure in the driver tube 
was limited to 2 atm to prevent overpressurization of the pressure transducers resulting from reflection of the detonation wave from the end wall or primary diaphragm. A $0.381 \mathrm{~cm}$ (.015 in) thick Mylar diaphragm separated the driver and driven tubes. The driven tube was open to atmosphere for the shock tube simulation experiments. Both the upstream and downstream propagation modes were simulated. Also, the effect of turbulence enhancement in the driver tube and helium dilution of the hydrogen/oxygen mixture were investigated.

Transient pressure traces at selected axial stations for the "upstream propagation" mode are shown in Fig. 10, and the plot of wave propagation speed vs. distance is shown in Fig. 11. The two pressure traces to the left of Fig. 10 are from transducers located in the driver tube, whereas the other four traces are from transducers in the driven tube. Although a large pressure is generated by the upstream propagating detonation wave, the diaphragm was not ruptured until the return of the reflected detonation wave to the diaphragm. The velocity plot shows that transition to a CJ detonation wave occurred in the vicinity of $27 \mathrm{~cm}$ from the ignition source, which is comparable to measurements of detonation wave formation distance from the basic PDE experiments. The CJ detonation wave was clearly not established prior to passage of the wave past the first transducer upstream of the diaphragm, and we speculate that the gradual rise in pressure associated with the detonation wave formation was insufficient to cause diaphragm rupture. A thinner diaphragm is clearly needed in this case. Diaphragm rupture did occur upon impact of the reflected detonation wave, generating a strong shock wave $\left(M_{S} \approx 3.5\right)$ in the driven tube. Note the abrupt rise in pressure upon passage of the shock wave, compared to the gradual rise in pressure associated with passage of the detonation wave. This "precompression" phenomena appears to be a characteristic of weak detonation waves, and generally disappears when a full $\mathrm{CJ}$ detonation wave is formed. ${ }^{15}$ Relatively good agreement is observed between the measured pressure ratio and the value predicted from Eq. (2) using the measured wave speed in the forward part of the driven tube. The measured pressure ratios indicate an attenuation of wave speed that is not observed from the time-of-flight measurements.
The tests with turbulence enhancement via a Shchelkin spiral ${ }^{29}$ produced rather surprising results. Turbulence enhancement actually delayed the formation of a $C J$ detonation wave in the driver tube, with a maximum wave propagation speed of only about $2000 \mathrm{~m} / \mathrm{sec}$, compared to the nearly $3000 \mathrm{~m} / \mathrm{sec}$ achieved for the $\mathrm{CJ}$ detonation wave. The maximum driver tube pressure levels were actually higher though, and little difference was seen in the strength of the shock wave generated in the driven tube.

A summary of measured driver tube pressure levels, driver and driven tube wave propagation speeds is shown in Fig. 12 for the "upstream propagation" mode. The shock speed in the driven tube appears to correlate better with the maximum pressure level attained in the driver tube rather than the detonation wave speed. Helium dilution did not exhibit the anticipated performance enhancement. In fact, shock velocities were actually lower. Furthermore, examination of the pressure traces for the helium dilution runs indicated a rather irregular wave pattern in both the driver and driven tubes. It appears that either inadequate mixing of the gases prior to ignition of the mixture or a lowering of the partial pressure of the hydrogen/oxygen mixture due to helium dilution may be a principal factor. Several investigators have emphasized the importance of âchieving good mixing to obtain strong detonation wave fronts. $^{23,30}$

Similar results were achieved for "downstream propagation" of the detonation wave, although lower detonation wave speeds and somewhat lower driven-tube shock speeds were observed for this mode. In general, $\mathrm{CJ}$ detonation waves did not form in the driver tube, probably due to the shorter distance traveled by the wave. This is not expected to be a problem for the full-scale driver tube, since the total length is approximately a factor of 10 greater than the distances required for transition to a CJ detonation wave in the basic PDE experiments. The pressure rise resulting from the impact of the downstream-propagating detonation wave should produce immediate rupture of the diaphragm, thus establishing the necessary conditions for strong shock formation in the driven tube. 


\section{Concluding Remarks}

Results of a design study to upgrade the performance of the UTA Hypersonic Shock Tunnel by converting from a pressure-driven to detonation-driven mode of operation have been presented. Experimental simulations of the detonation-driven shock tube were conducted by reconfiguring an existing pulse detonation engine research chamber. Both upstream and downstream propagation of the detonation waves were investigated. The "downstream propagation" mode was selected as the basis of operation of the full scale facility. This was due in part to the necessity of achieving a high pressure level for proposed MHD accelerator channel experiments without exceeding the 6000 psi pressure limit of the existing tunnel. Furthermore, the gradual rise in pressure behind the upstream-propagating detonation wave during its transition from a weak to a $\mathrm{CJ}$ wave may cause unsteady wave formation in the driven tube due to changing $p_{5}$ pressure levels. Hardware requirements for the facility modification have been identified, and cost estimates for necessary modifications have been prepared. We anticipate that the tunnel modifications will require approximately three months to implement. The resulting tunnel modifications will provide the required simulation capability needed to support research on MHD-augmented hypersonic test facility concepts. Furthermore, implementation of the driver modifications should greatly enhance the hypersonic test capability at UTA.

\section{Acknowledgments}

The authors would like to acknowledge the contributions and support provided by Dr. Y.M. Lee and Mr. Gloyd Simmons of MSE, Inc. during the course of this study, and to express their thanks to Mr. Dennis Bushnell of NASALangley for the original suggestion to investigate the detonation-driven shock tunnel concept. Also, valuable discussions with Dr. John Erdos of GASL are gratefully acknowledged. The study was funded in part by MSE, Inc. through Contract No. 95-C294-F (Dr. Y.M. Lee, technical contract monitor). Additional support was provided by the State of Texas Advanced Technology Program through Grant No. 003656056 (Dr. D. Johnston, program monitor).

\section{References}

1. "Proceedings of the MARIAH Workshop," MSE, Inc., Fairmont Hot Springs, Montana, November 1995.

2. Chinitz, W., Bakos, R.J. and Erdos, J.I., "Experimental Requirements for the Study of Shock-Induced Premixed Combustion," AIAA Paper No. 94-3099, 1994.

3. "Proceedings of the Magnetohydrodynamics (MHD) Technical Review and Planning Workshop," NASA, Washington, D.C., February 1995.

4. Rittenhouse, L.E., Pigott, J.C., Whoric, J.M. and Wilson, D.R., "Theoretical and Experimental Results With a Linear Magnetohydrodynamic (MHD) Accelerator Operated in the Hall Current Neutralized Mode," AEDC-TR-67-150, 1967.

5. Pate, S.R., Siler, L.G., Stallings, D.W. and Wagner, D.A., "Development of an MHDAugmented, High Enthalpy, Shock Tunnel Facility," AIAA Journal, Vol. 12, No. 3, March, 1974, pp. 289-297.

6. Simmons, G.A., Nelson, G.L., Hiers, R.S. and Western, A.B., "An Unseeded Air MHD Accelerator Concept for High Mach Number Hypersonic Propulsion Testing," AIAA Paper 89-2535, 1989.

7. Simmons, G.A., Nelson, G.L. and Lee, Y.M., "Analysis of Unseeded Nonequilibrium MHD Accelerator Concept for Hypersonic Propulsion Ground Testing Applications," AIAA Paper 92-3994, 1992.

8. Stuessy, W.S., Murtugudde, R.G., Lu, F.K. and Wilson, D.R., "Development of the UTA Hypersonic Shock Tunnel," AlAA Paper 90$0080,1990$.

9. Lu, F.K., "Initial Operation of the UTA Shock Tunnel," AIAA Paper 92-0331, 1992.

10. "Summary of Capabilities of Hypersonic Shock Tunnels at Calspan ATC," Calspan Advanced Technology Center, Buffalo, NY. 
11. "Description of the Aachen Shock Tunnel TH2," Shock Wave Laboratory, Technical University of Aachen, Aachen, Germany, January 1991.

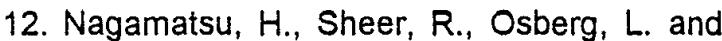
Cary, K., "Design Features of the General Electric Research Laboratory Hypersonic Shock Tunnel," GE Research Lab Report No. 61-RL-2711C, May 1961.

13. Eitelberg, G., Mclntyre, T.J., Beck, W.H. and Lacey, J., "The High Enthalpy Shock Tunnel at Gottingen," AIAA Paper 92-3942, 1992.

14. Bakos, R.J. and Erdos, J.I., "Options for Enhancement of the Performance of ShockExpansion Tubes and Tunnels," AIAA Paper 95-0799, 1995.

15. Stanley, S.B, Stuessy, W.S. and Wilson, D.R., "Experimental Investigation of Pulse Detonation Wave Phenomena," AIAA Paper 95-2197, 1995.

16. Stanley, S., Burge, K. and Wilson, D. "Experimental Investigation of Pulse Detonation Wave Phenomena as Related to Propulsion Application," AIAA Paper 952580, 1995.

17. Bird, G.A., "A Note on Combustion Driven Shock Tubes," In "Hypersonic Facilities in the Aerodynamics Department, Royal Aircraft Establishment," P.A. Hufton (Ed.), AGARD Report 146, 1957.

18. Coates, P.B. and Gaydon, A.G., "A Simple Shock Tube With Detonating Driver," Proc. Royal Soc. (London), A283, 1965, pp.18-32.

19. Balcarzak, M.J. and Johnson, M.R., "The Gaseous-Detonation Driver and Its Application to Shock Tube Simulation Techniques," In Proc. 5th Intl. Shock Tube Symp., Z.I. Slawsky, J.F. Moulton and W.S. Filler (Eds.), U.S. Naval Ordinance Lab, White Oak, MD, 1966, pp. 1111-1128.

20. Lee, B.H.K., "Detonation Driven Shocks in a Shock Tube," AIAA Journal, Vol. 5, No. 4, April 1967, pp. 791-792.
21. Yu, H.R ., Esser, B., Lenartz, M. and

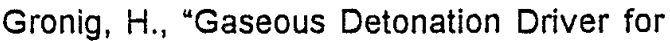
a Shock Tunnel," Shock Waves, Vol. 2, 1992, pp. 245-254.

22. Tamagno, J., Calleja, J. and Erdos, J., "Exploratory Tests of Detonation-Driven Expansion Tube Performance," NASA CR191580, General Applied Science Laboratories, Ronkonkoma, NY, March 1994.

23. Engers, R.J., Calleja, J.F. and Bakos, R.J., "A Detonation Driven Injectant Heater for Pulse Facility Testing Applications," AIAA Paper 95-3153, 1995.

24. "Thermal Equilibrium Program for Windows User's Manual," Software and Engineering Associates, Inc., 1992.

25. Gordon, S. and McBride, B.J., "Computer Program for Calculation of Complex Chemical Equilibrium Compositions, Rocket Performance, Incident and Reflected Shocks, and Chapman-Jouguet Detonations," NASA SP 273, 1971.

26. Angelone, J.P., "Shock Tube - High Temperature Gasdynamic Studies," M.S. Thesis, The University of Texas at Arlington, 1978.

27. Anderson, J.D., Jr., Modern Compressible Flow, 2nd ed., McGraw-Hill Publishing Co., New York, 1990.

28. Bussing, T. and Pappas, G., "An Introduction to Pulse Detonation Engines," AIAA Paper 94-0263, 1994.

29. Shchelkin, K.I., Soviet Journal of Technical Physics, Vol. 10, 1940, pp. 823-827

30. Ting, J.M., Bussing, T.R.A. and Hinkey, J.B., "Experimental Characterization of the Detonation Properties of Hydrocarbon Fuels for the Development of a Pulse Detonation Engine," AIAA Paper 95-3154, 1995. 


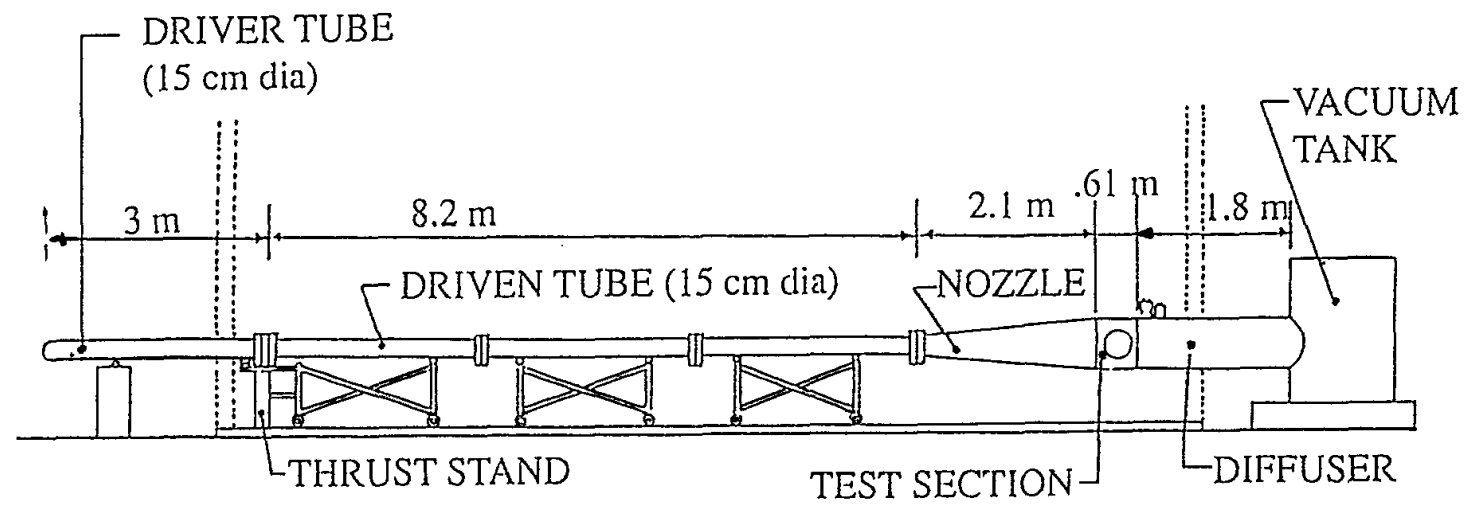

Fig. 1 Elevation view - hypersonic shock tunnel

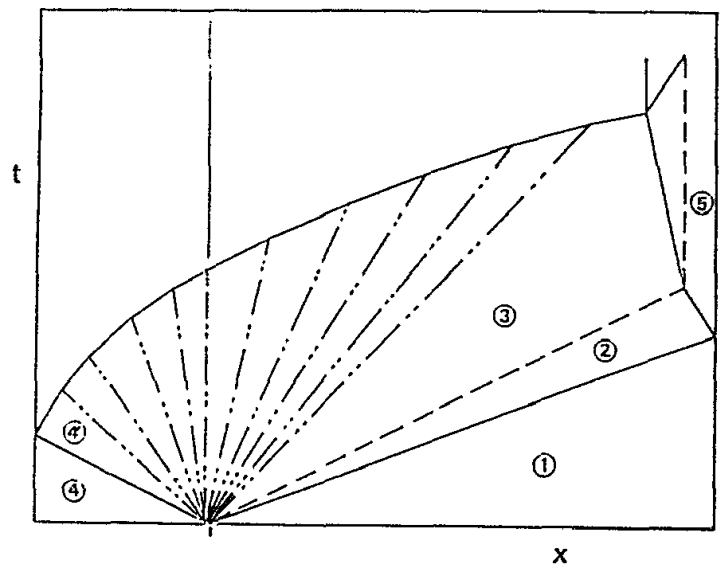

Fig. 2 Wave diagram for a detonation-driven shock tube with upstream propagation of the detonation wave

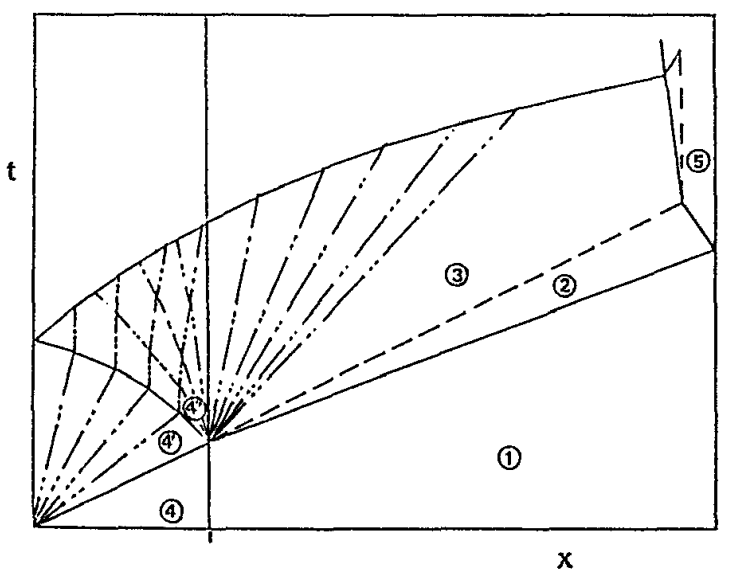

Fig. 3 Wave diagram for a detonation-driven shock tube with downstream propagation of the detonation wave

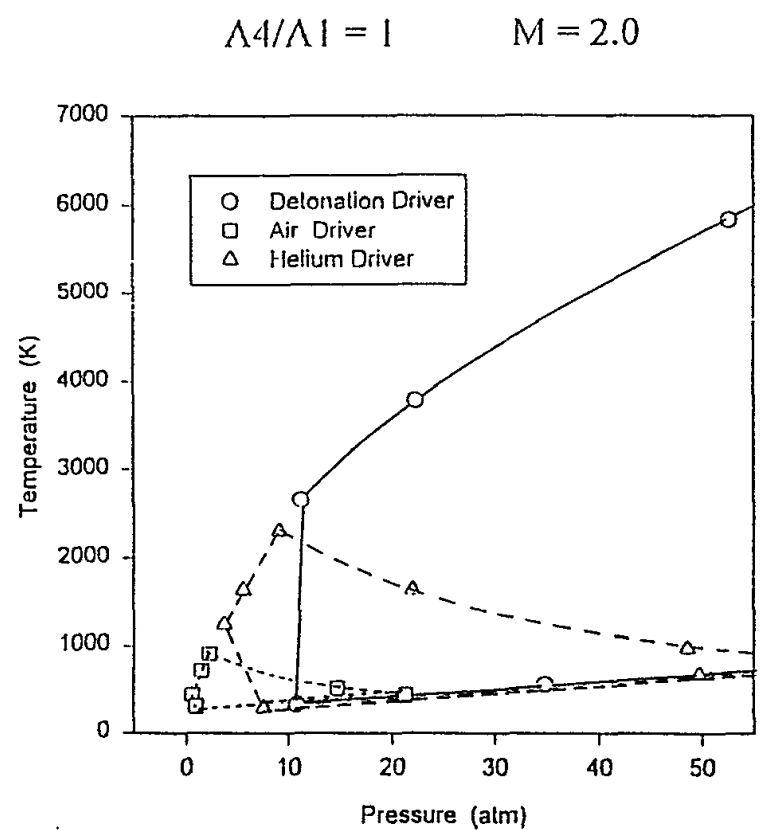

Fig. 4 Performance map for the detonation driven shock tunnel, $\mathrm{H}_{2} / \mathrm{O}_{2}=2.0$, Mach 2 nozzle 


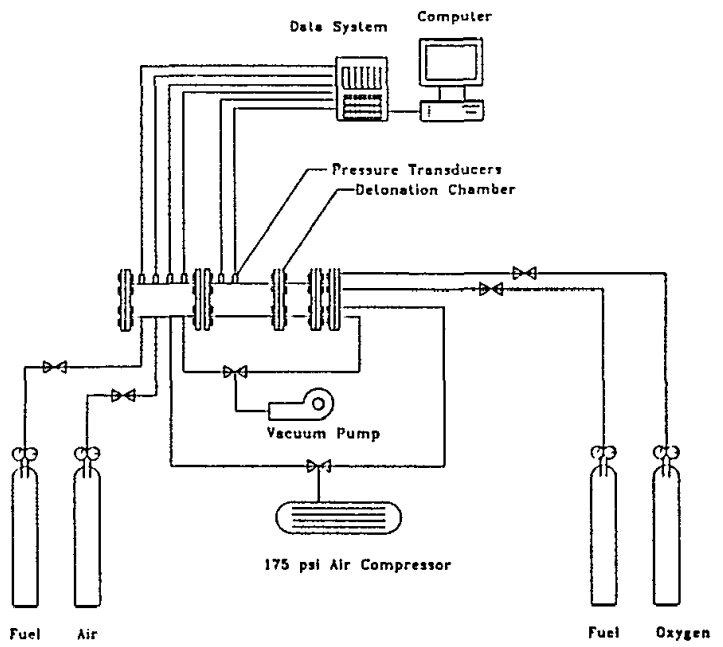

Fig. 5 Schematic diagram of PDE test facility
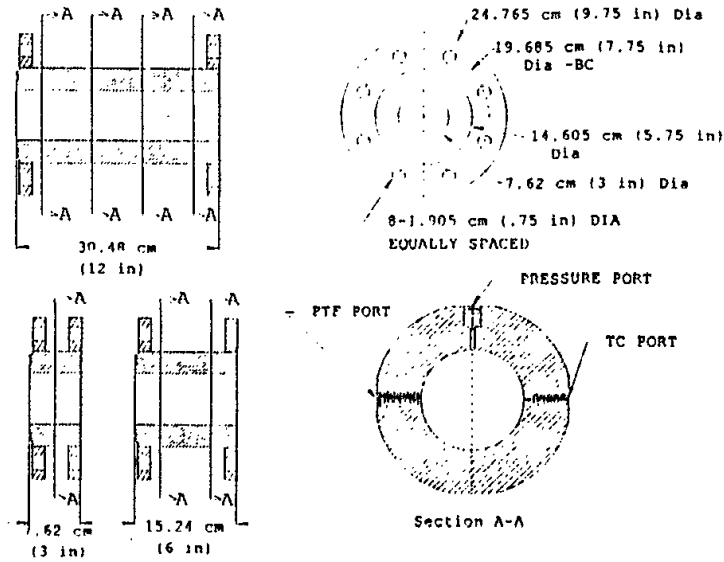

Fig. 6 PDE research combustion chamber

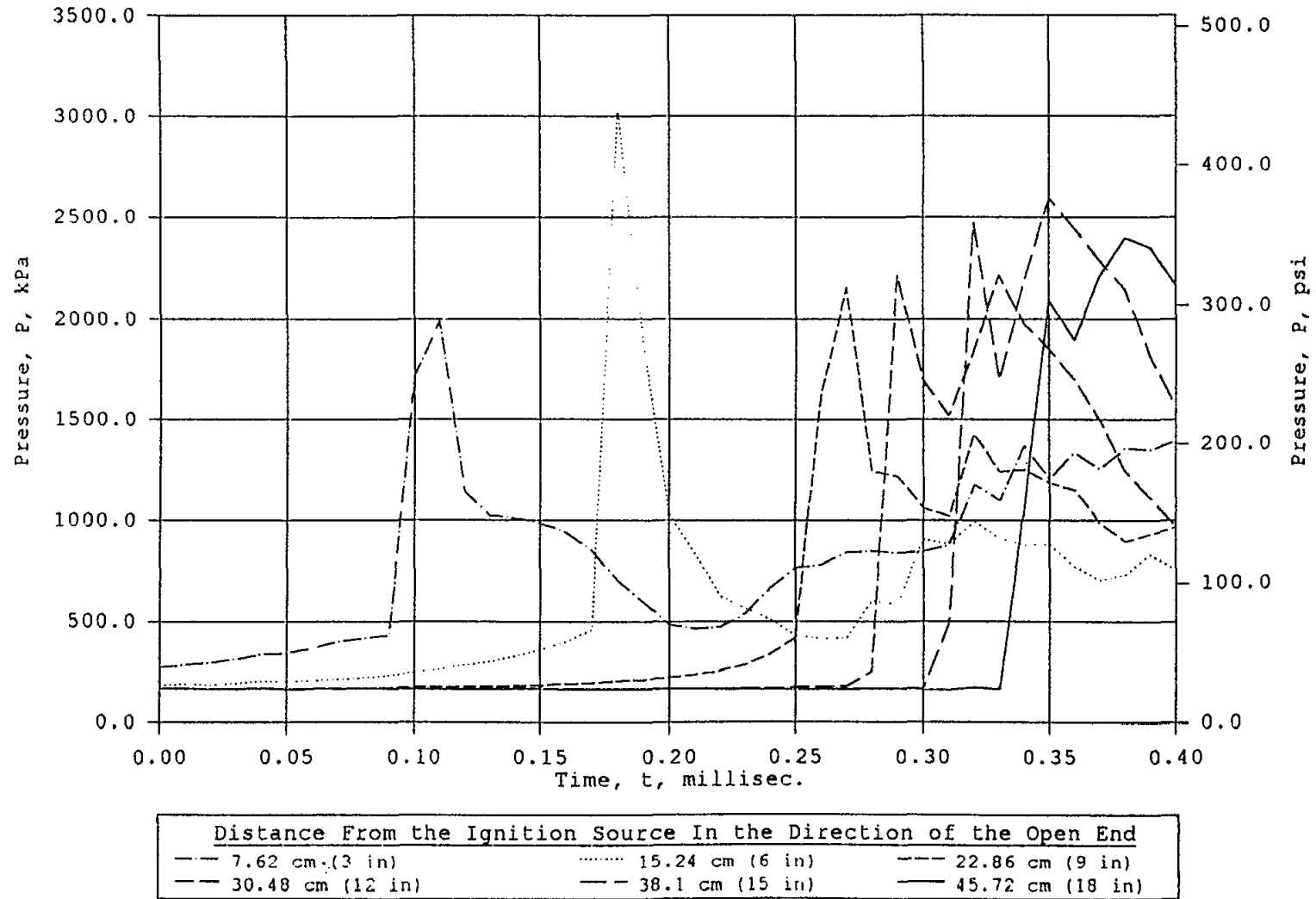

Fig. 7 PDE pressure plots for $\mathrm{H}_{2} / \mathrm{O}_{2}=2.0$ at an initial pressure of $2 \mathrm{~atm}$ 


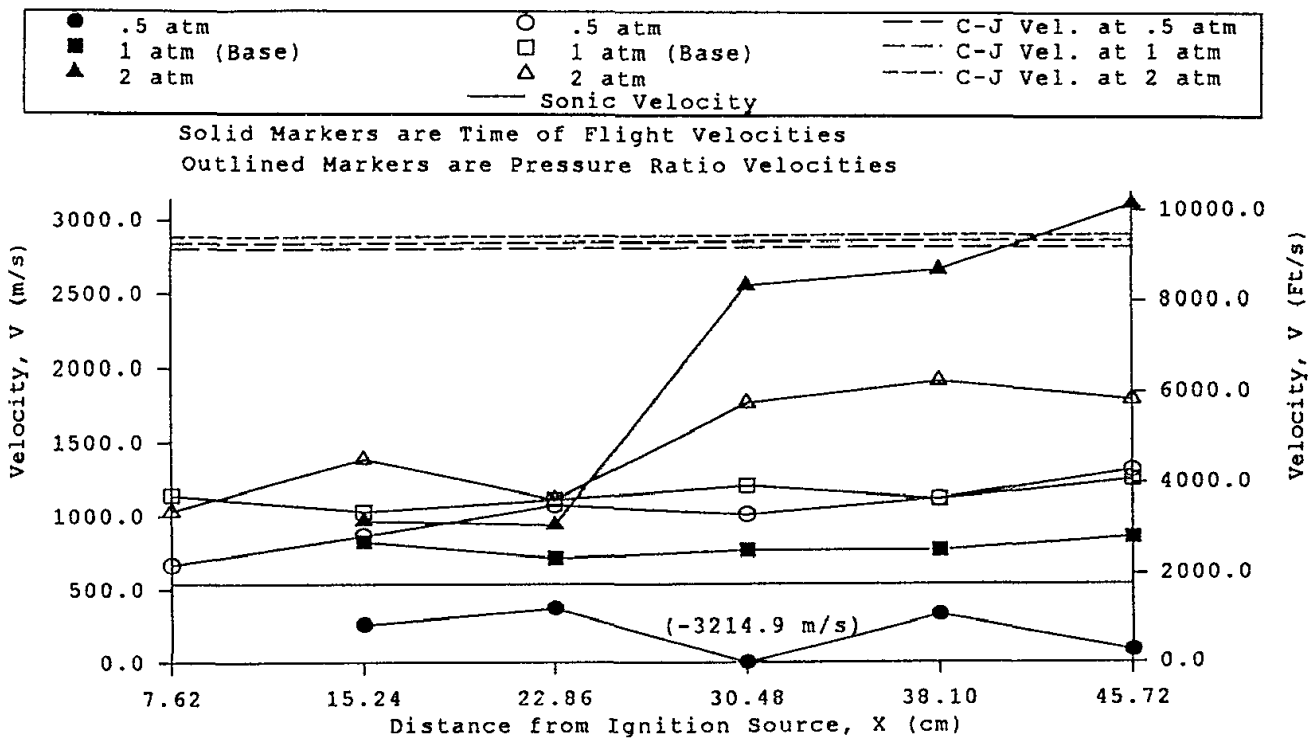

Fig. 8 PDE velocity plot ror $\mathrm{H}_{2} \mathrm{O}_{2}=2.0$ as a function of initial pressure

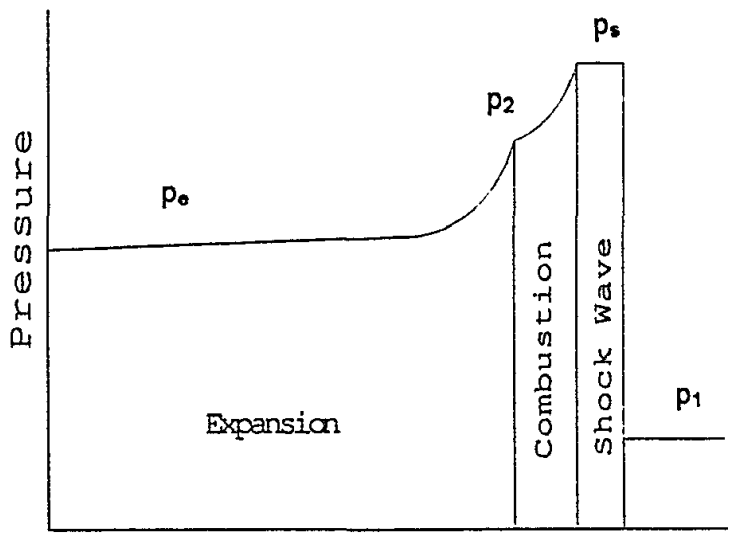

Distance

Fig. 9 ZND detonation wave model

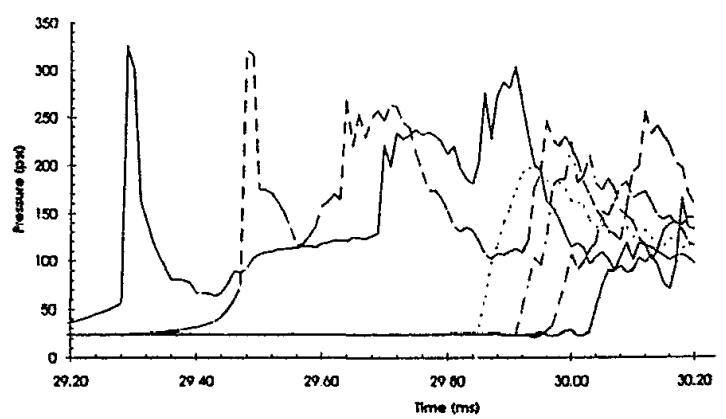

Fig. 10 Shock tube pressure plot for $\mathrm{H}_{2} / \mathrm{O}_{2}=$ 2.0 at an initial pressure of $2 \mathrm{~atm}$

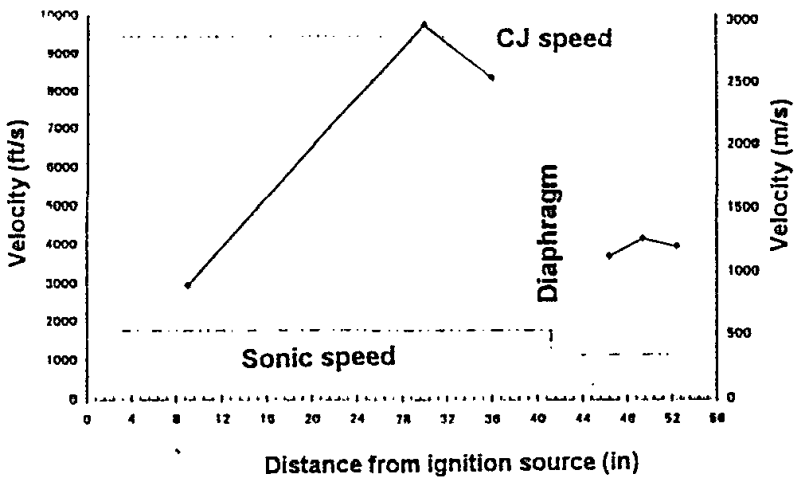

Fig. 11 Shock tube velocity plot for $\mathrm{H}_{2} / \mathrm{O}_{2}=2.0$ at an initial pressure of $2 \mathrm{~atm}$

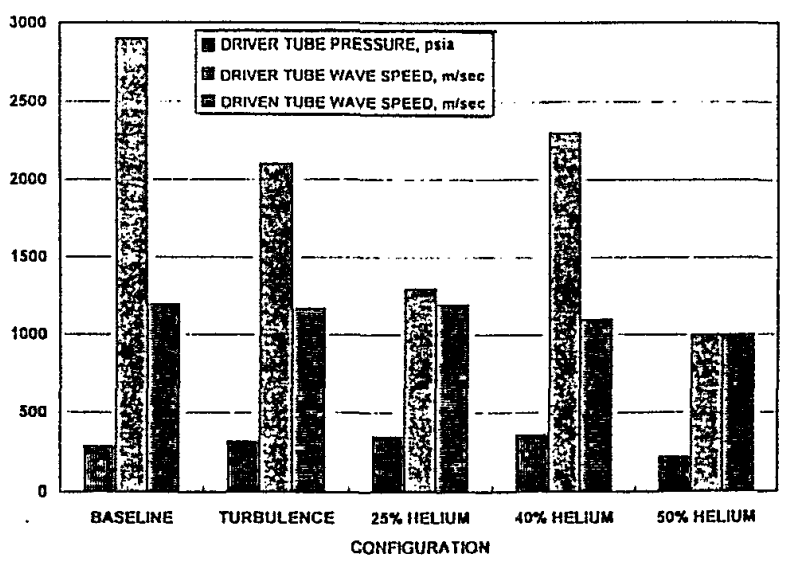

Fig. 12 Summary of upstream propagation test runs 